\title{
Inclusão digital, educação e desenvolvimento econômico: alguns marcos do debate
}

\section{RESUMO}

O presente artigo reflete sobre a presença das TIC (Tecnologias de Comunicação e Informação) em ambientes educacionais. A discussão que segue tem por objetivo identificar alguns marcos do debate sobre o investimento em tecnologia e educação como uma pré-condição para o desenvolvimento econômico. Inspirado pelas idéias de Milton Santos, o texto destaca também a necessidade de se considerar a dimensão humana na pesquisa e análise do uso dos objetos técnicos.

\section{PALAVRAS-CHAVE}

- inclusão digital

- desenvolvimento econômico

- educação

\section{ABSTRACT}

The present paper draws upon the presence of ICT (Information and Communication Technologies) within the educational environment. The following discussion aims at identifying some keystones of the debate concerning the investment on technology and education as a pre-condition to economic development. Inspired by Milton Santos' work, the text also highlights the necessity of bringing the human dimension into the research and analysis on technical objects.

\section{KEY WORDS}

- digital inclusion

- economic development

- education

\section{Fabio Josgrilberg UMESP}

$\mathbf{N}$ a discussão sobre a presença das tecnologias de informação e comunicação (TIC) na educação, uma das primeiras e fundamentais questões é não reduzir a questão técnica a um debate sobre objetos técnicos. Nesse sentido o pensamento de Milton Santos é particularmente inspirador. Para o geógrafo, a técnica pode ser descrita como o "conjunto de meios instrumentais e sociais com os quais o homem realiza sua vida, produz e, ao mesmo tempo, cria espaço". ${ }^{1}$ No caso particular das TIC, as técnicas envolvem "objetos técnicos" específicos, como o computador ou as redes de telecomunicação, e uma série de instrumentos sociais que ajudam os seres humanos a criarem "espaços", esse "conjunto indissociável de sistema de objetos e de sistemas de ações". ${ }^{2}$

É característico que as técnicas nunca apareçam sozinhas, mas como sistema de técnicas. ${ }^{3}$ Por mais que se valorize a transmissão por sinais digitais, há uma série de relações sociais e de outros instrumentos que se associam simultaneamente. As questões técnicas relativas à Internet, portanto, não se reduzem a problemas de infra-estrutura ou acesso. É de fundamental importância entender que, ao se assumir o conceito de técnica, o humano e o não-humano não são dissociáveis. ${ }^{4}$ As técnicas se articulam na relação dialética dos sujeitos com o objeto técnico de maneira situada; mais precisamente, trata-se de uma relação dialética com o "espaço" enquanto sistema constituído de objetos técnicos e ações humanas.

Santos retoma o conceito de intencionalidade, via Husserl, entre outros autores, para pensar a ação dos seres humanos e a produção do espaço. Nas suas palavras, "essa noção [intencionalidade] é igualmente eficaz na contemplação do processo de produção e produção das coisas, considerados como um resultado da relação entre o homem e o mundo, entre o homem e seu entorno". ${ }^{5}$ Há, portanto, uma "inseparabilidade dos objetos e das ações" ${ }^{6}$ O geógrafo discute não apenas a intencionalidade nas ações humanas, mas também a do próprio objeto técnico. “Então, à intencionalidade da ação se conjuga a intencionalidade dos objetos e ambas são, hoje, dependentes da respectiva carga de ciência e de técnica presente no território". ${ }^{7}$

Sobre a intencionalidade do objeto técnico, vale notar aqui que, em sentido semelhante, Merleau-Ponty falava do modo como as coisas sugerem uma maneira de "seduzir, atrair, de fascinar o sujeito livre que se encontra confrontado a ela"8 ou um "estilo de ser das coisas". ${ }^{9}$ Assim, a ação humana é dotada de intencionalidade e visa ao mundo. Este, porém, não é simples objeto para um pensamento livre, mas pólo dialético de uma relação ambígua. O objeto técnico se 
ensina ao ser humano e sem a ação subjetiva ele não seria nada. De maneira situada, "forma e vida são os pólos da produção do conhecimento" ${ }^{10}$

A técnica, como "conjunto de meios instrumentais e sociais com os quais o homem realiza sua vida", ${ }^{11}$ desenvolve uma racionalidade que lhe é própria.

A técnica alimenta a estandardização, apóia a produção de protótipos e normas, atribuindo ao método apenas a sua dimensão lógica, cada intervenção técnica sendo uma redução (de fatos, instrumentos, de forças e meios), servida por um discurso. A racionalidade se impõe às expensas da espontaneidade e da criatividade, porque ao serviço de um lucro a ser obtido universalmente. É dessa forma que a técnica se torna autopropulsiva, indivisível, auto-expansiva e relativamente autônoma, levando consigo a respectiva racionalidade a todos os lugares e grupos sociais. ${ }^{12}$

No período atual, a racionalidade das técnicas se impõe em suas dimensões social, econômica e tecnológica por força de uma mais-valia que opera globalmente e um imaginário que lhe corresponde. ${ }^{13} \mathrm{~A}$ técnica, portanto, é produto da história, mas também produtora de história; ${ }^{14}$ história que no presente momento é marcada pelo desenvolvimento de estruturas desiguais, movidas pela circulação restrita de informação, ${ }^{15}$ assim como pela concentração do poder econômico. Sobre isso, a análise de Ianni continua precisa:

Note-se, no entanto, que as maravilhas da ciência e da técnica não se traduzem necessariamente na redução ou eliminação das desigualdades sociais entre grupos, classes, coletividades ou povos. Ao contrário, em geral preservam, recriam ou aprofundam as desigualdades. Tanto é assim que, nas últimas décadas do século $X X$, as ciências sociais estão elaborando conceitos como os de "desemprego estrutural", "subclasse" e "Quarto mundo", ou recuperando noções de "marginalidade", " periferia", "pobreza", "miséria" e "exclusão", para caracterizar as coletividades e, às vezes, povos inteiros. ${ }^{16}$

Uma das novidades do período técnico recente é a chamada exclusão digital, que é apenas uma dimensão da exclusão social e se caracteriza pela "distância relativa do acesso a produtos, serviços e benefícios das novas tecnologias de informação e comunicação entre diferentes segmentos da população" ${ }^{17}$ Questão cada vez mais presente nos debates da gestão pública, verifica-se um processo de inclusão, ainda que limitado, que busca expandir o acesso às TIC. O objetivo é reduzir as diferenças entre os setores sociais com condições reais de participação no período técnico atual, motivado pelas lógicas das redes e dos flu- xos de informação intensos, e os que apenas sofrem com as conseqüências do avanço tecnológico.

Embora a expressão "exclusão digital" seja um termo recente, o debate sobre os desequilíbrios nos fluxos comunicacionais e de acesso às mídias já data de algumas décadas. As primeiras grandes reflexões sobre o tema se deram nos anos 1970. Em meados dessa década, as discussões giravam em torno da Nova Ordem Econômica Mundial (NOEI), cujas preocupações levaram ao processo de elaboração das bases para as propostas de uma Nova Ordem Mundial da Informação e da Comunicação (NOMIC). Na ONU, particularmente na UNESCO, esse debate teve seu ápice com a publicação do Relatório MacBride, no início da década de 1980, onde já se lia: “deve-se dar a máxima importância para eliminar desequilíbrio e disparidades na comunicação e suas estruturas, e particularmente nos fluxos de informação" ${ }^{18}$

O debate sobre a NOMIC se esfriou, em parte, a partir de 1983, com a decisão dos Estados Unidos e da Inglaterra, no ano seguinte, de se retirarem da UNESCO - as razões são parcialmente atribuídas às direções das discussões sobre a própria NOMIC. Durante o resto da década de 1980 e década de 1990, as reflexões sobre os desequilíbrios dos fluxos comunicacionais e informacionais ficaram restritas a uma série de organizações não-governamentais e a alguns espaços acadêmicos, mas de maneira muito dispersa. ${ }^{19}$

É na virada do século, com a expansão da Internet, das redes de telecomunicações e dos sistemas digitais que a questão dos fluxos comunicacionais e de infraestrutura voltaram a concentrar as atenções não só de pesquisadores ou ativistas, mas de governos e empresários que buscavam regulamentar as novas condições técnicas. $\mathrm{O}$ debate cresceu com a iminência da primeira fase da Cúpula Mundial sobre a Sociedade da Informação $\left(\mathrm{CMSI}^{20}\right)$, em 2003, na Suíça, evento organizado pela ONU em parceria com a ITU (International Telecommunications Union) - a agência da ONU mais próxima do setor privado e que reúne as principais empresas de telecomunicações do planeta. No âmbito da sociedade civil, destaque-se nesse período a campanha CRIS (Communication Rights in the Information Society ${ }^{21}$ ), o crescimento do movimento de software livre e posteriormente de licenças copyleft para outros conteúdos como a iniciativa Creative Commons. $^{22} \mathrm{Na}$ CMSI, diversos temas da NOMIC foram retomados, talvez de forma não intencional em alguns casos, mas pelo simples fato de os problemas das décadas passadas persistirem sob novas formas.

No novo cenário, governos, ONGs, muitas vezes em parceria com o setor privado, articulam-se em projetos isolados ou políticas públicas dos mais variados tipos para combater a "exclusão digital". As razões dos stakeholders desse processo de inclusão se alimentam de interesses econômicos e de motivações ligadas à defesa dos direitos humanos, ainda que nem sempre esses empenhos andem juntos.

O enfoque apenas no objeto técnico pode, no en- 
tanto, ser equivocado. As iniciativas de democratização do acesso às TIC devem vir acompanhadas de uma série de outras ações para de fato combater a exclusão social em sentido amplo. Por si só, as políticas de democratização do acesso à informática têm um impacto limitado. Há que se reconhecer, porém, que, independentemente das outras dimensões do processo excludente, a distância dos novos objetos técnicos marcam profundamente as possibilidades de atuação de indivíduos e países no período técnico-científico-informacional. Se para participar desses novos tempos, uma das metas é conectar as pessoas pelas redes de telecomunicações, não há como deixar de verificar zonas de pobreza evidentes. Como sugeriu Santos, "a medida da pobreza é dada antes de mais nada pelos objetivos que a sociedade determinou para si própria". ${ }^{23}$ Portanto, a caracterização da pobreza vai além de dados estatísticos que aferem o nível de renda ou consumo, pois não se trata apenas de uma "categoria econômica, mas também uma categoria política acima de tudo". ${ }^{24}$

No âmbito dos grandes acordos internacionais, diversos documentos da ONU abordam a questão do acesso à tecnologia, a começar pela Declaração universal dos direitos humanos. No Artigo 27.1, lê-se: "Toda a pessoa tem o direito de tomar parte livremente na vida cultural da comunidade, de fruir as artes e de participar no progresso científico e nos benefícios que deste resultam" ${ }^{25}$ Há outros documentos importantes que tocam o tema tais como a Declaração sobre o progresso social e o desenvolvimento (1969), a Declaração sobre o uso do progresso científico e tecnológico no interesse da paz para o benefício da humanidade (1975) e a Convenção da Unesco sobre educação técnica e vocacional (1989). Mais recentemente assinou-se a Declaração do milênio (2000), que resolve, no Artigo 20, "assegurar que os benefícios das novas tecnologias, especialmente tecnologias de informação e comunicação, em conformidade com as recomendações contidas na Declaração Ministerial ECOSOC 2000, estejam ao alcance de todos". Por último, vale citar o Plano de ação e a Declaração de princípios aprovados na Cúpula Mundial sobre a Sociedade da Informação (CMSI), cuja segunda fase se realizou em dezembro de 2005.

No Plano de Ação aprovado na primeira fase da CMSI, por exemplo, lê-se:

Com base nos objetivos de desenvolvimento acordados internacionalmente, incluindo os da Declaração do Milênio que são premissas da cooperação internacional, metas indicativas podem servir como referências globais para aumentar a conectividade e acesso no uso das TIC na promoção dos objetivos do Plano de Ação, a serem alcançados até 2015. Estas metas podem ter em conta o estabelecimento de metas nacionais, considerando as diferentes circunstâncias nacionais: (a) conectar todos os vilarejos com
TIC e estabelecer pontos de acesso comunitário; (b) conectar universidades, faculdades, escolas secundárias e primárias com TIC; (c) conectar centros científicos e de pesquisa com TIC; (d) conectar bibliotecas públicas, centros culturais, museus, correios e arquivos com TIC; (e) conectar centro de saúdes e hospitais com TIC; (f) conectar todos os departamentos de governos local e central e estabelecer websites e endereços de correio eletrônico; (g) adaptar o currículo de todas as escolas primárias e secundárias para atender os desafios da Sociedade da Informação, levando-se em consideração as circunstâncias nacionais; (h) assegurar que toda a população do mundo tenha acesso a serviços de rádio e televisão; (i) encorajar o desenvolvimento de conteúdo e das condições técnicas para facilitar a presença e uso de todas as línguas do mundo na Internet; (j) assegurar que mais da metade dos habitantes do mundo tenham acesso às TICs ao seu alcance. ${ }^{26}$

Como se vê, a participação na chamada Sociedade da Informação entrelaça a necessidade técnica com a preocupação de oferecer uma educação condizente ao novo momento. No Plano de Ação da CMSI, a atenção ao ensino infantil e fundamental é demonstrada na indicação da necessidade de conectar todas as escolas e na orientação para adaptação do currículo, ainda que não se detalhe como seriam desenvolvidas essas alterações. Embora a questão do currículo seja uma discussão que ultrapasse os objetivos deste artigo, vale, ao menos, se referir às reflexões no âmbito da UNESCO, braço da ONU para educação e cultura e participante da CMSI. Conforme o World Report 2005: Towards Knowledge Societies (Em direção às sociedades do conhecimento), uma das competências básicas que deverão ser desenvolvidas no período escolar é a capacidade para "aprender a aprender", ou seja, deve-se ensinar os alunos, entre outras coisas, a "localizar, classificar e selecionar a informação que agora é encontrada em qualquer parte" $^{27}$

Para além das discussões sobre os direitos humanos e o acesso à tecnologia e à informação, há também uma série de relatos que buscam justificativas econômicas para a democratização do acesso à informática, debate que fica evidente por uma literatura que se proliferou desde a década de 1970 e que circula em ambientes ideológicos diversos. Para Marcelo Cortês Neri, chefe do Centro de Pesquisas Sociais do IBRE/FGV, por exemplo, "a ID [inclusão digital] representa um canal privilegiado para a criação de oportunidades de geração de renda e de cidadania da nossa desigual sociedade em plena era do conhecimento. Basta lembrar que na lista das 10 maiores fortunas do mundo, a maior parte deriva da nova economia". ${ }^{28}$ Em estudo comparativo realizado na Grã-Bretanha, Itália, Israel, Noruega e Alemanha, 
Haisken-DeNew e D'Ambrosio sugerem haver uma relação clara entre o uso ou acesso às TIC e a redução da exclusão social e econômica..$^{29}$

Ao debate centrado nas possibilidades de desenvolvimento econômico a partir da democratização do acesso à informática alia-se, não raramente, um discurso sobre os investimentos na educação, área que hoje já não pode ser separada do objetivo de preparar os alunos para atuarem, em relações profissionais ou não, com o suporte das TIC. Um estudo feito pela Economist Intelligence Unit em parceria com The IBM Institute for Business Value, por exemplo, atribui um peso de $15 \%$ ao "Ambiente cultural e social" em sua avaliação que estabelece o ranking de e-readiness dos países. ${ }^{30}$ A categoria leva em consideração, entre outros fatores, os níveis educacionais e de alfabetização digital (e-litteracy) do país. Lato sen$s u$, o e-readiness é uma tentativa de medir até que ponto as nações estão aptas a participar da Sociedade da Informação, levando em conta não só a infraestrutura de telecomunicações e informática, mas também a capacidade dos cidadãos para usar as novas tecnologias e o suporte e transparência do governo e legislação para ações nessa área. Apenas a título de comparação, segundo o ranking, o Brasil aparece em terceiro lugar na América Latina, atrás de México e Chile.

Nas novas relações sociais, educação e acesso à tecnologia andam de mãos dadas. Assim como há argumentos em favor do investimento em infra-estrutura de telecomunicações para sustentar o desenvolvimento econômico, há também para a educação. Veja-se, por exemplo, as tentativas de relacionar os níveis de educação às possibilidades econômicas encontradas no volume 42 de Finance $\mathcal{E}$ Development, publicação quadrimestral do Fundo Monetário Internacional (FMI). Nessa conservadora revista, ainda que não se faça do setor educacional "tábua de salvação", as relações com as condições gerais da economia são amarradas por um dos autores:

Capital humano é importante, mas não é a única coisa que governa o funcionamento de uma economia. Não há dúvidas de que características básicas como o desenvolvimento de sistema de direito de propriedade, limites na intrusão governamental por meio de taxas e regulações e a abertura dos mercados de trabalho e produto tem um enorme impacto. Forçar os resultados da escola em uma economia incapaz de utilizá-los dificilmente tem efeitos positivos. ${ }^{31}$

Em resumo, o valor do investimento em educação passa, para o autor, pelo resultado econômico que ele possa gerar e que depende das condições locais em termos de legislação e atuação do governo.

Mesmo entre autores mais progressistas, a constatação sobre o vínculo da educação com a tecnologia não é negado, ainda que as motivações e argumentos mu- dem. Castells, ao reconhecer a capacidade tecnológica como fonte de competitividade na economia global sugere que "o sistema educacional dotado de recursos humanos com as qualificações e em quantidades necessárias" sustentará a articulação da ciência, tecnologia, gerenciamento e produção. ${ }^{32}$ Em outro texto, o autor também é enfático: "Educação, informação, ciência e tecnologia tornam-se as fontes decisivas de criação de valor na economia baseada na Internet". ${ }^{33}$

A rapidez das transformações impressiona, mas é incontestável. Há até argumentos de que os países em desenvolvimento podem realizar o salto direto ao período técnico atual sem passar pelos estágios anteriores; processo conhecido nos debates econômicos internacionais como technological leap-frog, que poderia ser traduzido como salto tecnológico. ${ }^{34}$ Concebe-se, por exemplo, que mesmo em áreas de baixa conectividade, carente de qualquer meio que se possa imaginar, seria possível acesso à Internet de banda larga por tecnologias wireless (sem fio). ${ }^{35} \mathrm{Um}$ caso típico de preocupação entre idealizadores de projetos desse tipo é o meio rural pobre. Argumenta-se, por exemplo, que a nova geração de tecnologias wireless pode ser incorporada em regiões rurais de maior escassez graças a sistemas de cooperativas que mobilizem as comunidades, aumentando o potencial de alavancar novas redes para além das possibilidades locais e independentemente de a região ser do interesse das grandes empresas de telecomunicações. ${ }^{36}$

Contudo, se não parece razoável contestar a velocidade do desenvolvimento técnico, é totalmente necessário pôr em questão a desigualdade existente no processo de expansão das técnicas do período atual. Ainda que o salto tecnológico de um período para outro seja uma hipótese técnica, é possível identificar, em muitos casos, a falta de interesse político e econômico para sustentar tais projetos. No dizer de Santos,

o espaço nacional fica dividido entre áreas onde os diversos aspectos da vida tendem a ser regidos pelos automatismos técnicos e sociais próprios à modernidade tecnicista e áreas onde esses nexos estão menos, ou quase nada presentes. Seria uma oposição entre espaços inteligentes, racionais, e espaços opacos, não racionais ou incompletamente racionais, comandando uma nova divisão regional do país e determinando novas hierarquias: entre regiões com grande conteúdo em saber (nos objetos, nas instituições e empresas, nas pessoas) e regiões desprovidas dessa qualidade fundamental em nossa época; entre regiões do mandar e do fazer. ${ }^{37}$

As diferenças regionais se tornaram sociais, não mais naturais, pois se fundam na maior ou menor densidade dos sistemas técnicos, que são a base material para a organização do trabalho, da terra, do siste- 
ma financeiro, entre outras atividades. ${ }^{38}$ Ainda que tecnicamente o leap-frog seja facilmente concebível, forjar as condições sociais para realizar essa tarefa é algo extremamente complexo. Como a técnica só existe sob a ação humana, é mais realista imaginar a coexistência de diferentes sistemas técnicos por um bom tempo, dados os diversos interesses em jogo. Apesar de todo o processo de sedimentação cultural sobre a necessidade de expansão do acesso às TIC, seja por razões econômicas ou de direitos humanos, ou pelos dois motivos, o que se vê é uma tendência para a proliferação dos objetos técnicos apenas em locais ou regiões onde existam mercados lucrativos. Portanto, permanece pertinente a reflexão de que os pobres sofrem a "dupla desvantagem", pois há cada vez mais produtos para os segmentos que as indústrias consideram lucrativos e cada vez menos produtos populares. ${ }^{39}$ Em geral, o argumento é que, cedo ou tarde, os produtos de alta tecnologia se tornam mais baratos e daí seguem sua expansão. Esse é um dos discursos, por exemplo, em relação às novas TVs digitais. Contudo, é nesse ínterim de acomodação do objeto técnico à sociedade, cultural e economicamente, que as distâncias entre e intra-regiões se acentuam.

No novo período técnico-científico-informacional, a economia global é marcada por sua "interdependência, assimetria, regionalização, crescente diversificação dentro de cada região, inclusão seletiva, segmentação excludente e, em conseqüência de todos esses fatores, por uma geometria extraordinariamente variável que tende a desintegrar a geografia econômica e histórica" ${ }^{40}$ Dada essa tendência seletiva, Castells entende haver um processo que ameaça excluir regiões inteiras, como parte da África, por exemplo. ${ }^{41} \mathrm{~A}$ rede funcionaria sem essas populações; afastamento recíproco a partir do rompimento da conexão ou da incapacidade de conectar.

Se a desconexão de populações inteiras já faz parte do horizonte de análise, a eliminação da tensão já é uma outra história. $\mathrm{O}$ aumento da pressão social aumenta em filigrana e, por vezes, as rupturas se dão de forma incompreensível, em alguns casos criminosas, deixando os analistas atônitos e o discurso político sem referências claras. Esse foi o caso, por exemplo, da seqüência de incêndios nas periferias de várias cidades francesas. A barbárie não se justifica; é inconcebível queimar carros com pessoas dentro. No entanto, parte da motivação daqueles jovens franceses parecia ser "Queimo, logo existo", ${ }^{42}$ mesmo que as pessoas atingidas fossem da própria comunidade, ou seja, os que sofrem com os incendiários. Outro indício das tensões do novo período técnico são os fluxos migratórios e retorno dos fundamentalismos nas mais variadas dimensões: cultural, econômica, religiosa, entre outras, seja no oriente ou no ocidente, no norte ou no sul.

Com já se discutiu alhures, não seria o caso de questionar, em uma reflexão de caráter dialético, se "o Ser excluído, explorado, não seria constitutivo do poder da Rede?". ${ }^{43}$ A tensão não permanece mesmo quando a rede desconecta o Ser? Também não é demais lembrar, com Ianni, que a racionalidade capitalista, mesmo sob o suporte das TIC, é sempre instável; que as fases de maior fluxo e trocas são também as mais propícias para as rupturas

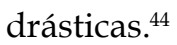

Até entre aqueles que participam da propalada "sociedade em rede" há desequilíbrio evidente. Os vetores de direção e as velocidades não são os mesmos. Os fixos e os fluxos são interdependentes, ${ }^{45}$ mas as condições de participação diferem. As ações no período técnico-científico-informacional obedecem a tempos diferentes. A ubiqüidade das técnicas que articulam a rede não homogeneíza o espaço. ${ }^{46}$ Por essas razões, a análise deve se dirigir não só à infra-estrutura, mas às ações. "Levando em conta o seu [da rede] aproveitamento social, registram-se desigualdades de uso e é diverso o papel dos agentes no processo de controle e regulação do seu funcionamento" ${ }^{47}$ Mesmo os que estão conectados à rede vivenciam-na sob condições distintas, desequilibradas e, por vezes, altamente desumanizadoras. Não é à toa que os sites mais visitados no Brasil e no mundo pertencem aos grandes grupos de mídia, em parceria com empresas de telecomunicações, entre outras.

Nas fábulas que alimentam esse novo cenário é comum encontrar debates sobre a "lógica das redes". De fato, a metáfora da rede inspira solidariedades diversas, inimagináveis num passado recente, e caracteriza muito bem aspectos fundamentais do período técnico atual. No entanto, há que se ler criticamente também essa metáfora, especialmente as interpretações que entrelaçam estar conectado à igualdade de condições de participação no período técnico atual. O modelo imaginado é o da rede distribuída, sem um centro preciso e em que todos os pontos são receptores e produtores de informação. Para participar, basta utilizar o mesmo protocolo de transmissão e recepção de dados.

"Aprender em rede", "rede do conhecimento", "trabalho em rede", "redes de solidariedade": a rede se tornou o modo de descrever uma série de relações sociais importantes com benefícios a serem destacados. Contudo, a metáfora também pode estar intrinsecamente ligada às propostas capitalistas neoliberais mais predatórias possíveis. A lógica é a mesma: indivíduos (pontos) em contato, obedecem às mesmas regras (protocolos), que devem acima de tudo facilitar a livre troca de informação (produtos), sob igualdade de condições, sem interferências do Estado (um centro organizador). Quem não seguir os protocolos, sofre as sanções merecidas (desconexão): embargos comerciais, fechamento das linhas de crédito, aumento do risco-país, entre outras.

Mesmo na educação, a idéia de aprendizado em rede tem lá seus limites. Os educandos não são de maneira alguma indivíduos sob igualdade de condi- 
ções no processo educativo. Não se tratam apenas de pontos a serem conectados. É preciso respeitar a singularidade e as possibilidades de cada um. Cada um poderá se destacar em momentos diferentes e outros necessitarão de ajuda para não se "desconectarem" do processo. O educador continua sendo fundamental na articulação dos conteúdos. Não dá para imaginar que a rede por si só alimentará o processo educativo. Como ensinou Paulo Freire, "uma educadora nunca pode se omitir. Uma educadora nunca pode esconder-se diante dos alunos. Ela nunca pode ter vergonha de ser uma educadora. Quer dizer, ela tem que assumir-se como educadora, como quem educa". ${ }^{48}$ Portanto, "o papel do professor, da professora, é mais do que simplesmente abrir caminho. É o de quem também mostra o caminho". ${ }^{49}$

O espaço escolar, portanto, se situa nesse período técnico-científico-informacional, com o seu respectivo imaginário e suas ambigüidades. Nessa encruzilhada de objetos e ações humanas, há toda uma fábula sobre as TIC aliadas à educação. As possibilidades alimentam os mitos soteriológicos nos vários espectros políticos. A educação, aliada à tecnologia, seria teoricamente capaz de forjar novos caminhos para o desenvolvimento econômico, diminuir a desigualdade e de estabelecer novos vetores de direção nos fluxos comunicacionais, bem como novos modos de aprender e ensinar.

É certo que, exageros à parte, as TIC e a racionalidade que lhes acompanha de fato reorganizam sob vários aspectos as relações sociais, profissionais, científicas e educativas. No entanto, o risco do deslumbramento com o período técnico-científicoinformacional está permanentemente sendo alimentado em discursos de gestores públicos, mídia e até mesmo de educadores. Nota-se, em muitos casos, a tentativa de dar soluções com ênfase no objeto técnico para problemas sociais, políticos e econômicos, dos quais o objeto técnico é apenas o suporte.

A força motriz desse imaginário encontra parte de suas razões em um sonho comum. Como escreveu Eliade sobre o período industrial, "o mito soteriológico [dos alquimistas] do aperfeiçoamento e, em última análise, da redenção da Natureza sobrevive, camuflado, no programa patético das sociedades industriais". ${ }^{50}$ Os sonhos e os ideais dos alquimistas de acelerar o trabalho do tempo e transformar o metal ordinário em ouro, ${ }^{51}$ é possível afirmar, também mostra sua força ainda nos dias de hoje. "O homem moderno assume a função da duração temporal: em outros termos, coloca-se no lugar do Tempo" ${ }^{52}$

No entanto, a fé nas possibilidades da ciência e dos novos objetos técnicos não dá conta de eliminar as tensões alimentadas pela percepção de que no novo período técnico mudou o mundo, mas não necessariamente desenvolveu relações humanas mais fraternas. Na análise de Morin, "a pior ameaça e a maior promessa chegam ao mesmo tempo ao sécu- lo". ${ }^{53}$ A todo tempo, a humanidade parece esbarrar na "imaturidade para realizar-se a si mesma" ${ }^{54}$ Os avanços técnicos que abrem tantos caminhos também trazem "uma ameaça de aniquilamento (nuclear, ecológico) e temíveis poderes de manipulação" ${ }^{55}$

O paradoxo da promessa e da ameaça é um traço comum à incorporação de novos objetos técnicos por uma sociedade em qualquer período da humanidade. Há uma constante tensão entre tendências de integração e tendências de desintegração, entre um processo civilizatório alavancado pela tecnologia e um movimento contrário ("decivilization"). ${ }^{56} \mathrm{Um}$ exemplo simples desse fenômeno: a informática que coloca pessoas em contato (processo civilizatório), também aumenta a demanda por energia em um mundo já sob desequilíbrio ecológico (descivilização). Outros exemplos como a genética, e as questões éticas em jogo, e o automóvel, que mata tanto quanto algumas guerras, dão testemunhos desse paradoxo. Em cada cultura, para evitar a destruição, há movimentos de auto-regulação que buscam identificar os usos possíveis do novo objeto técnico e verificar o que é aceitável. Nesse processo, que limita a ação destruidora, a ênfase não é nos objetos técnicos; como observou Elias, trata-se de uma questão de humanos para humanos. ${ }^{57}$

\section{Há, portanto, a}

necessidade de se politizar completamente o debate sobre a tecnologia e suas relações com a ciência e com o capital, em vez de deixar que ela continue sendo tratada no âmbito das políticas tecnológicas dos Estados ou das estratégias das empresas transnacionais como quer o establishment. $^{58}$

Não dá para acreditar que, como afirmou o Conselheiro de Educação, Ciência e Tecnologia do governo de Extremadura, Espanha, que "a bondade de um mercado falsamente livre levaria a uma Sociedade da Informação para todos" 59 . As regiões pobres, com baixa densidade de sistemas técnicos, se vêem diante do desafio, já com bastante atraso, de forjar as condições necessárias para o mínimo de participação de seus habitantes, que mesmo "desconectados" sofrem as influências das redes por contato. No que se refere à democratização do acesso à informática e ao papel do computador na escola, gestores públicos, docentes e alunos se encontram justamente nesse cruzamento de interesses econômicos e luta pelos direitos humanos em relação à comunicação e aos avanços tecnológicos da sociedade; entre forças integradoras e desintegradoras; civilização e barbarismo. O momento, portanto, exige um posicionamento de todos os envolvidos. O que é aceitável ou não? Quais os caminhos da auto-regulação?

Apesar das dúvidas, receios e mesmo sonhos, o fato é que as técnicas do novo período se expandem vertiginosamente; o objeto técnico se instala no am- 
biente escolar de maneira irreversível, com ou sem planejamento. Seja por pressão dos pais que, criticamente ou não, exigem os laboratórios de informática, seja por visão dos administradores, movida por ideais de uma escola que consiga dar conta das várias dimensões da sociedade atual ou por simples interesse eleitoreiro. mFamecos

\section{NOTAS}

1. SANTOS, M. A natureza do espaço: técnica e tempo, razão e emoção. São Paulo: Edusp, 2002, p. 29.

2. Ibidem, p. 21.

3. Ibidem, p. 54 .

4. Ibidem, p. 24.

5. Ibidem, p. 90.

6. Ibidem, p. 95 .

7. Ibidem, p. 64 .

8. MERLEAU-PONTY. M. Causeries: 1948. Paris: Seuil, 2002, p. 27.

9. Ibidem, p. 33.

10. SANTOS, M. A natureza do espaço, op. cit., p. 97.

11. Ibidem, p. 29.

12. Ibidem, p. 182.

13. Ibidem, p. 181.

14. Ibidem, p. 181.

15. Ibidem, p. 184.

16. IANNI, O. Teorias da globalização. 5 ed. Rio de Janeiro: Civilização Brasileira, 1988, p. 157.

17. SORJ, op. cit., p. 62.

18. MACBRIDE, S (Org.). Many Voices, One World: Towards a New More Just and More Efficient World Information and Communication Order. Nova Iorque: UNESCO; Kogan Page; WACC, 1988, p. 253

19. Cf. SIOCHRÚ, S. O (Org.). Le premier débat sur les droits de la communication. In: Manuel d'evaluation dês droits de la communication. Londres: CRIS, 2005, p. 17-20.
20. WORLD SUMMIT ON THE INFORMATION SOCIETY. Disponível em: http:/ / www.wsis.org. Acesso em: 10 jan. 2006.

21. COMMUNICATION RIGHTS IN THE INFORMATION SOCIETY (CRIS). Disponível em: <http:// www.crisinfo.org/>. Acesso em: 10 jan. 2006.

22. CREATIVE COMMONS. Disponível em: http:/ / www.creativecommons.org.br>. Acesso em: 10 jan. 2006.

23. SANTOS, M. Pobreza urbana. 2 ed. São Paulo: Hucitec, 1979, p. 9

24. Ibidem, p. 10.

25. ONU. Declaração universal dos direitos do homem. Disponível em: <http:// www.unhchr.ch/udhr/lang/por.htm>. Acesso em: 31 jan. 2006.

26. WORLD SUMMIT ON THE INFORMATION SOCIETY. Plan of action. Document WSIS-03/ GENEVA/DOC/5-E. 12 Dez 2003.

27. UNESCO. World Report 2005: Towards Knowledge Societies. Paris: United Nations Educational Scientific and Cultural Organization, 2005. p. 74 .

28. NERI, M.C. Inclusão digital e combate à miséria. In: Valor Econômico, 1 de abril de 2003, A11.

29. HAISKEN-DELNEW, J.P. \& D'AMBROSIO, C. ICT and Social-economic Exclusion. In: RWI Discussion Paper, No. 3. Disponível em: <http:/ /ssrn.com/abstract $=433220$. Acesso em: 31 jan. 2006.

30. ECONOMIST INTELLIGENCE UNIT; IBM INSTITUTE FOR BUSINESS VALUE. The 2005 e-readiness rankings. Disponível em: http:/ / graphics.eiu.com/files/ad_pdfs/ 2005Ereadiness_Ranking_WP.pdf $>$. Acesso em: 22 dez. 2006, p. 21.

31. HANUSCHEK, E. Why Quality Matters in Education. In: Finance \& Development, Volume 42, Número 2, Jun. 2005. Disponível em: <http:/ / www.imf.org/external/pubs/ft/fandd/2005/ 06/hanushek.htm>. Acesso em 12 jan. 2006.

32. CASTELLS, M. A sociedade em rede. ol 1. 4 ed. Trad. Majer, R. V. Rio de Janeiro: Paz \& Terra, 2000.

33. Idem. A galáxia da internet: reflexões sobre a 
internet, os negócios e a sociedade. BORGES, M.L.X. (Trad.). Rio de Janeiro: Jorge Zahar, 2003, p., 216.

34. MANSELL, R. OECD Emerging Market Economy on Eletronic Commerce. Disponível em: http://www.gapresearch.org/production/ ecomm-emerging-markets.pdf $>$. Acesso em: 10 jan. 2005.

35. ORGANISATION FOR ECONOMIC CO-OPERATION AND DEVELOPMENT (OECD). OECD Input to the United Nations Working Group on Internet Governance. Disponível em: <http://www.oecd.org/dataoecd/34/9/ 34727842.pdf>. Acesso em: 2 jan. 2005.

36. GIRARD, B.; SIOCHRÚ, S. O. Communitybased Networks and Innovative Technologies: New Models to Serve and Empower the Poor. Nova Iorque: United Nations Development Programme, 2005. p. 17.

37. SANTOS, M. A urbanização brasileira, op. cit., p. 49.

38. Ibidem, p. 51.

39. Idem. Pobreza urbana, op. cit., p. 69

40. CASTELLS, M. A sociedade em rede, op. cit., p. 123.

41. Ibidem, p. 131.

42. GLUCKSMANN, A. Les feux de la haine. Le Monde. Disponível em: <http:/ / www.lemonde.fr/web/article/0,1-0@2-3232,36712474,0.html>. Acesso em 11 jan. 2006.

43. JOSGRILBERG, F. B. “Tecnologia e sociedade: entre os paradoxos e os sentidos possíveis". In: Comunicação \& Educação, ano X, nº 3, set/dez. São Paulo: CCA/ECA/USP; Paulinas, 2005. p. 280.

44. IANNI, O. Teorias da globalização. 5 ed. Rio de Janeiro: Civilização Brasileira, 1988. p. 188.

45. SANTOS, M. A natureza do espaço. São Paulo: Edusp, 2002, p 277.

46. Ibidem, p. 267.

47. Ibidem, p. 268.

48. FREIRE, P. Pedagogia dos sonhos possíveis. Freire, A. M. A. (Org.). São Paulo: Editora Unesp, 2001, p. 109.
49. Ibidem, p. 109.

50. ELIADE, M. Ferreiros e alquimistas. LACERDA, R.C. (Trad.) Rio de Janeiro: Zahar Editora, 1979.

51. Ibidem, p. 42 e p. 138.

52. Ibidem, p. 139.

53. MORIN, E. Uma mundialização plural. In: MORAES, D. (Org.). Por uma outra comunicação: mídia, mundialização cultural e poder. Rio de Janeiro: Record, 2003, p. 365

54. Ibidem, p. 362.

55. Ibidem, p. 358.

56. CF. ELIAS, N. Technization and Civilization. In: The Nobert Elias Reader. Oxford: Balckwell Publishers, 1998, p. 212-229.

57. Ibidem, p. 214.

58. SANTOS, L.G. Politizar as novas tecnologias: o impacto sócio-técnico da informação digital e genética. São Paulo: Editora 34, 2003, p. 11.

59. MIGUEL, L.M.V. Os poderes públicos como garantia de uma sociedade do conhecimento para todos. In: SILVEIRA, S.A. (Org). Software livre e inclusão digital. São Paulo: Conrad, 2003, p. 217. 